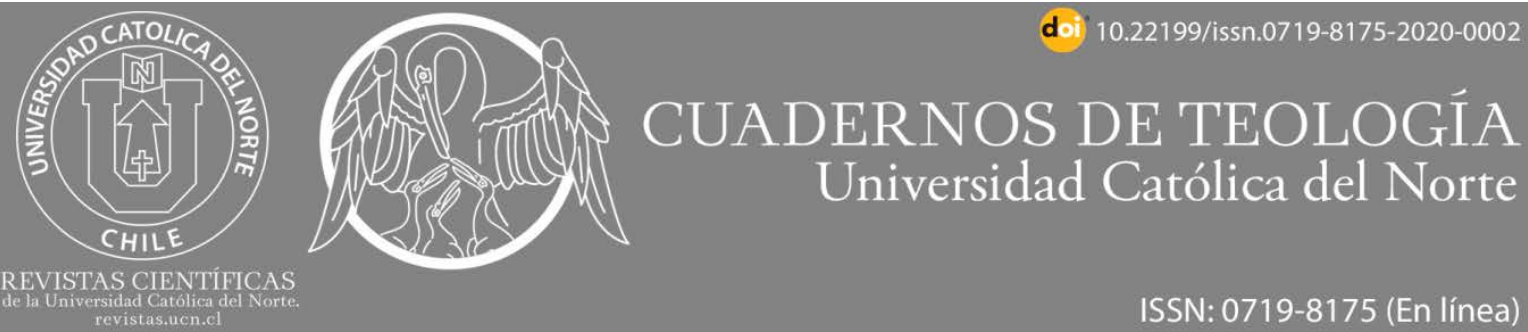

\title{
La presencia de religión en la educación y escuelas chilenas
}

\section{Presence of religion in chilean's education and schools}

\author{
Javier F. A. Vega Ramírez' (10 orcid.org/0000-0002-0335-1557 \\ ${ }^{1}$ Universidad Austral de Chile. Académico. Instituto de Ciencias de la Educación, Valdivia, Chile. Magíster en \\ Educación, mención Políticas y Gestión, U. Austral de Chile. \\ @javier.vega@uach.cl \\ (cc) BY
}

\section{Resumen:}

La presencia de la Iglesia Católica en la historia de la educación chilena ha sido permanente desde sus orígenes, experimentando los últimos años una complejización de la relación Iglesia con Educación, por interpretarse la Escuela como una prolongación de la acción pastoral de la Iglesia, en detrimento de otras funciones. Para clarificar esta relación desarrollaremos un estudio sobre religión, iglesia y escuela analizando la generación de modelos educativos desde la historia del cristianismo, la manera en que desarrollan educación los agentes de diversas iglesias en el sistema oficial. Finalizando con una breve relación de los conflictos principales que se ha enfrentado en la historia de Chile en esta relación entre iglesias al interior de la Educación.

Palabras Clave: Cristianismo; Relación Iglesia - Educación; Planificación de la educación.

\section{Abstract:}

The presence of the Catholic Church in the history of Chilean education has been permanent since its origins. In recent years, the relationship between the Church and education has become more complex because the school has been interpreted as an extension of the Church's pastoral activity, to the detriment of other functions. To clarify this relationship, we will develop a study on religion, church and school, analyzing the generation of educational models from the history of Christianity, the way in which the agents of various churches in the official system develop education. We will end with a brief relation of the main conflicts that have been faced in the history of Chile in this relation between churches within Education.

Keywords: Christianity; Church and Education; Educational planning. 


\section{El desarrollo de la Educación desde el Cristianismo}

\subsection{El acto educativo}

La Educación es un acto común al ser humano. No es posible desarrollar la existencia sin aprender, de hecho cada uno de los teóricos de la educación parte de la base que la Educación en sí es tan innato al ser humano como cualquier otro acto animal (León Salazar, 2007). La diferencia la constituye la conciencia del proceso de aprendizaje. De ahí que el proceso de educación sea al mismo tiempo un acto natural, dado que aprendemos de lo que vivimos y observamos, como un acto moral, debido a que podemos ir discerniendo y seleccionando tipos y oportunidades del aprendizaje (Bárcena Orbe, 1989). Esta acción natural de aprender hace que, como todo acto humano, requiera cierta regulación social, por cuanto la sociedad en su conjunto se ve beneficiada del aprendizaje colectivo (Ramírez Iñiguez, 2017).

No aprendemos por lo tanto sólo para nosotros mismos, sino que aprendemos para otros y en relación con otros (Boff, 2002), y por lo mismo las formas de regulación de la vida social se preocupan del proceso de aprendizaje (Jara Hinojosa, 1998). Desde la vida familiar hacia la vida comunitaria, tribal o de grupos más amplios se hace deseable una cierta porción de aseguramiento de qué es lo que podemos aprender como un mínimo que asegura cierta pervivencia de la sociedad y su vida común, regulación que conlleva el desarrollo de determinados aspectos éticos, actitudinales, de relación, de procedimientos y sus formas de asegurarlos.

\subsection{La Educación como acto humano}

Siendo entonces la Educación un acto humano, podemos preguntarnos qué relación se establece entre la Iglesia (o iglesias) y la Educación, puesto que las Iglesias son la forma de expresión sistemática de la experiencia primordial de lo trascendente, y por lo tanto es una institución ampliamente presente (Polanco, 2003). Para formular una respuesta podemos recurrir a las definiciones iniciales: la Educación es un acto común a todo ser humano, que toma un carácter de oficial cuando hay una intención detrás. ¿Cuál es la intención primordial de la Educación en todas las culturas?: la respuesta podría ser una y común "formar personas" (Ospina, 2008). En el caso del cristianismo, la intención de formar mejores personas desembocó tempranamente en un modelo educativo desarrollado en dos etapas, la primera vivida en torno a Jesús de Nazareth, que tenía la particularidad de ser al mismo tiempo un hombre de Galilea con un atractivo social suficiente como para provocar que le siguieran en vida multitudes, y también es (según su propio testimonio y el de sus seguidores) el hijo de Dios (Fernández Eyzaguirre, 2007). A esta primera etapa le podemos denominar "vivencial" por la proximidad de la experiencia del "maestro" en contexto vital. Esta fue la primera etapa del desarrollo de un modelo educativo, ¿cómo transcurrió este educarse de los primeros cristianos?. Transcurrió estando con Él, en comunidad con Él.

La segunda etapa del modelo educativo cristiano se produce inmediatamente después de la muerte, resurrección y ascensión de Jesús, que por su impacto debe haber resultado en un período confuso para todos los primeros discípulos, tanto que al poco 
tiempo se desplaza la forma de educarse. Antes se educaban estando con Él, y durante el tiempo pascual parecía que eso seguiría así, pero luego de la Ascensión este modelo ya no se sostiene. Ya no se tiene a Jesús para verlo respirar, caminar, comer, reír, celebrar y ser buena persona. Sólo subsiste su recuerdo, entonces el segundo modelo debe hacer una opción curricular: ¿qué es lo que se contará acerca de Él?, ¿de qué se hablará? (Den Heyer, 2003). Esta selección de contenidos, que tuvo su versión compacta en el Credo, es en realidad la opción de decir cuáles son los mínimos con los cuales se puede comenzar a compartir el contenido de la experiencia didáctica del encuentro con el dios humano (Villar, 1993).

Brotan así en torno a la experiencia de Jesús una dupla de modelos educativos, que se rescata de la tradición antigua: un primer modelo que se dedica a vivir con Jesús (modelo vivencial), y un segundo modelo que se dedica a predicar y confesar a Jesús (modelo testimonial). En los evangelios, hablando del primer modelo, tenemos bastantes datos muy abundantes respecto de cómo era la vida junto a Jesús. A Jesús no se le aprendía, sino que se le experimentaba. Vivir en torno a él era un experiencia fundamental que sólo quienes podían tener la capacidad de entender entendían (como lo resume el enigmático silogismo "el que tenga oídos que oiga") y quienes no tenían la capacidad dejaban pasar (Pagan, 2011).

El modelo educativo vivencial de los apóstoles había sido ya probado antes, con algunas diferencias, por la Academia de Platón y el Liceo de Aristóteles y los círculos peripatéticos, también iniciado por él, pero afianzados por Teofrastro (Calderón y González, 2006). Aunque el modelo fue imitado por muchos otros, había distancia de tiempo entre estar "con el maestro" y estar "en la propia casa". La experiencia cristiana resalta que Jesús es, a diferencia de estas experiencias, la vía para aprender, lo que se debía aprender y la forma en que se podía aprender. Jesús es, literalmente desde el punto de vista pedagógico, vía, contenido y modo del aprendizaje, y esto afectaba a todos. Estar con Jesús era relatado como un "estar en casa", tal como se conoce acerca de las primeras comunidades cristianas (Fernández Eyzaguirre, 2007).

Este segundo modelo pedagógico, el modelo de la vivencia comunitaria, dura hasta que Constantino y Licinio le ponen fin a las persecuciones, y liberan por un lado la práctica de la Religión y comienzan, por otro lado, a mirar con simpatía el cristianismo (Moreno Resano, 2013). La Escuela existente estaba principalmente asociada a los procesos de instrucción militar y a procesos de preparación elitista, habitualmente relacionados con filósofos de la época (De León Lázaro, 2013).

La escuela que comenzaba a cuajarse de la mano de la experiencia cristiana era distinta, con una "mística" particular difícil de mantener una vez que el cristianismo, apoyado por el emperador Teodosio, fue promovido a religión oficial del Imperio (Costa Grillo y Abreu Funari, 2015; Moreno Resano, 2013). Se comienza a instalar la equiparidad de ser Romano (ciudadano) a ser cristiano, con lo que ser parte de la administración del Estado pasa por ser cristiano (Andrades Rivas, 2017) provocando que el proceso de preparación para ser cristiano se elimine. De ahí que quienes quieren conservar la mística optan por arrancar del orden del mundo tradicional en un proceso denominado la "Fuga Mundi", huir 
del mundo como está para poder conservar lo más propio del ser cristiano, esto es, vivir juntos para recrear la experiencia de ser capaces de morir por la experiencia vivida o deseada de Jesús (Egido Serrano, 2013). Si bien este proceso no genera una división estricta en la Iglesia entre religión oficial (romana) y religión no oficial (la del desierto), sí provoca que la Escuela cristiana se organice en torno a los monjes del desierto (organizados en Cenobios) es una propuesta que favorece la posterior organización de la Escuela y Universidad, con mucha más innovación y novedad que lo que realizaba la Iglesia asociada al Imperio.

\subsection{Evolución de las propuestas educativas}

En este momento histórico queda el cristianismo de frente a un problema que engloba toda la experiencia pedagógica: ¿qué enseñar?, ¿para qué enseñar?. Asimismo pareciera confirmarse en la práctica que el modelo cristiano de comunidades de aprendizaje en torno a un cuerpo doctrinal estable, nutrido de reflexiones personales, aparato crítico de filósofos paganos y experiencia creyente, es una alternativa a continuar (Oliver, 2000). Estas experiencias se transforman en base de otros modelos cristianos educativos, como son las escuelas monásticas (asociadas al modelo educativo comunitario - interno - transformador del Cenobio) y las escuelas catedralicias (que sistematizan el proceso del modelo educativo adoctrinador de la Iglesia "oficial"), desarrolladas durante la Edad Media. Ya en el S. XII, producto de las luchas doctrinales y las persecuciones, llegan eruditos árabes a la península ibérica y traen el marco de pensamiento filosófico de Aristóteles, con Maimónides y Averroes, actualizando el marco neoplatónico tradicional de Avicena (González, 2007). A esto se suma otra de las novedades de la época, que es el hecho que muchas órdenes monásticas se mantienen organizadas como escuela de vida y muchas parroquias territoriales tienen asignados párrocos que comienzan a vivir solos, y por lo tanto, sin un contexto educativo pertinente (Morales, 2010).

Al término de la Edad Media Iglesia Católica contribuye con el afianzamiento de diversos modelos educativos: Un modelo vivencial de tipo monástico, que deriva en Escuelas catedralicias (posteriores universidades) y un modelo más doctrinal de tipo jerárquico, que deriva en fundaciones de misioneros, para expandir el modelo. Estos cuatro modelos subsisten hasta entrado el S. XIX cuando, de forma novedosa, mujeres consagradas empiezan a mirar su consagración como un llamado a reaccionar ante el sufrimiento del desvalido, entendiendo que el evangelio se predicaría con las obras y que esas obras mientras más concretas fueran, mayor fuerza de predicación tendrían (Faubell Zapata, 2000; García Ahumada, 2008a).

\section{La institución escolar}

\section{1. La fundación de las escuelas y su desarrollo en Chile}

El gran impulso misionero iniciado el S. XVI, sumado a la desconfianza contra el poder temporal de la Iglesia, que también se desarrolla durante el mismo siglo, hacen que el aporte de la Iglesia sea visto con mayor temor (Romero, 2004), por lo que se comienza a 
erigir otro referente sobre la propuesta educativa. Hasta antes de la Revolución industrial la educación era un asunto que se dividía entre el ámbito familiar laboral (el aprendizaje de un oficio) y el ámbito familiar elitista (aprendizaje de un cúmulo de conocimientos culturales que hacían la diferencia entre el trabajo y el estudio). Por todo esto la institución escuela no era requerida, sino que existían profesores a modo de instructores específicos que desarrollaban enseñanza libre de determinadas artes (Orellana Rivera, 2010; Serrano Pérez et al., 2012; Soto Roa y Núñez Prieto, 2004). Pero la Revolución Industrial exige que surjan las escuelas para obreros como una solución a la instrucción masiva de determinadas rutinas que, realizado individualmente, podría ser más lento y demoroso. Por su parte algunos teóricos como Fayol (1916), asumen que la industria realiza un triple proceso denominado "planificar, realizar y evaluar", pensando en una organización que fuera eficiente en su proceso productivo. Con el tiempo estos principios, establecidos en su obra "administración general e industrial", terminan finalmente modelando la escuela moderna.

Así tenemos que el surgimiento de la Educación grupal para obreros se ve aparejado con el surgimiento de escuelas para señoritas, con la misma intención práctica de aprendizaje de oficios o artes domésticas, y con el surgimiento de escuela de hombres que preparaban para la educación superior, que hasta inicios del S. XX no necesariamente desembocaba en la educación universitaria (Egaña Barahona et al., 2003). Tempranamente se dan tres tipos de instrucciones en el ámbito educativo, por un lado la instrucción para el trabajo (escuela de obreros), instrucción para el hogar (escuela de mujeres) e instrucción para la educación superior (escuela de hombres), todas de manera simultánea (Núñez Prieto, 2007 y 2010; Orellana Rivera, 2010; Ponce de León Atria, 2010).

Esta triple división se ve modificada por el surgimiento de mayores posibilidades económicas y de nuevas perspectivas de desarrollo sobre las ciencias educativas, pudiendo establecerse un punto de inflexión en el aporte de la psicología conductista y su posibilidad de establecer cánones de cumplimiento para el logro de determinados hitos en el desarrollo (Leiva, 2005). La psicología conductista aporta la doble comprensión que el ser humano no solamente puede aprender en determinados momentos de su desarrollo, sino que además puede ser comparado según su nivel de logro de aprendizaje, cuestión que termina por "humanizar" la visión de Fayol que había sido traspasado a la Escuela: ya no solamente es necesario evaluar en torno al cumplimiento de determinados productos, sino que además se hace necesario evaluar el logro en determinados procesos. La educación vive un proceso de definiciones sobre qué es necesario aprender para luego determinar qué es necesario evaluar. Con un desarrollo relativamente elitista con mínimos estandarizados - aprender a leer, aprender un oficio, aprender a llevar un hogar - (Congreso Jeneral de Enseñanza Pública, 1903) la educación va pasando de administrador en administrador, desde el hogar hacia la fábrica, y desde la fábrica hacia el Estado que busca asegurar el cumplimiento de los mínimos en pos de un proyecto de sociedad común (Serrano Pérez et al., 2012). Así el Estado de manera temprana busca asegurar su posición en la construcción de un proyecto de sociedad diferenciado del proyecto de sociedad que hasta ese momento habían propuesto solamente la Industria y la Iglesia Católica (Jara Hinojosa, 1998; Congreso Nacional Pedagójico, 1890). 
En el caso particular de Chile con la separación Iglesia - Estado iniciada en el gobierno de Federico Santa María (1844) y firmada como parte de la Constitución de 1925, durante el gobierno derechista de Arturo Alessandri Palma se inicia un proceso de duplicación de instituciones por parte del Estado sobre las que había levantado con relativa eficiencia la Iglesia Católica (Cementerios, Registro Civil, Educación). Esto origina que surja una educación religiosa (habitualmente reservada para las capas económicamente más privilegiadas de la sociedad) y una educación laica también iniciada en las capas económicamente más privilegiadas de la sociedad (que eran quienes podían educarse retrasando la fecha de ingreso al mundo del trabajo), pero con vocación de universalidad (Aedo-Richmond, 2000; Egaña Barahona et al., 2003; Senado de la República de Chile, 2005; Serrano Pérez et al., 2012). La educación obrera (escuelas técnicas, escuelas para obreros) en cambio, queda a disposición de ambos administradores, por parte de la Iglesia como elemento central de su misión entre las capas desposeídas de la sociedad, por parte del estado como elemento pragmático de capacitación para los oficios necesarios.

La irrupción de los principios tayloristas introduce una nueva perspectiva, colocando el énfasis en un currículo científico por sobre otras dimensiones, dando importancia al paradigma científico como el paradigma a utilizar en la organización de contenidos. El paradigma científico, que propone comprobar y confirmar cada hallazgo como parte del proceso de conocimiento, abre las puertas de par en par para la sistematización de procesos de Evaluación, por cuanto evaluar no solamente se hace parte del proceso, sino que es condición fundamental para que el proceso se desarrolle en un currículum que tiene como puntos fundamentales aprendizaje en áreas que se basan en datos concretos. Con esto en el currículum toman importancia asignaturas como Ciencias, Historia, Matemáticas y Lenguaje, y dejan de tener importancia al mismo nivel (aunque no desaparecen del proceso de enseñanza) asignaturas como Música, Artes o Higiene (actualmente Educación Física).

Un último cruce teórico influye directamente en Educación, y es el de la adopción de la teoría del Capital Humano (Schultz, 1961) como un elemento de comprensión de la importancia de la Educación, y por lo tanto de su necesidad de regulación (Levin, 2015; Sandoval Vásquez y Hernández Castro, 2018). Al ser la educación un factor diferencial entre el nivel de desarrollo de las economías mundiales (a mayor nivel educativo de un pueblo, mayor nivel de desarrollo económico) se hace necesario evaluar el nivel de influencia que se está logrando sobre la economía por determinados procesos educativos, de modo de ir seleccionando los más eficientes y de mayor calidad, ambos términos provenientes de la lógica económica con sentido productivo. Actualmente tenemos el desarrollo de un modelo educativo fuertemente ligado a la economía, con alto énfasis en la verificación de los aprendizajes por la comprensión de su directa relación con el desarrollo económico como nación. En el caso particular de Chile la opción por ser incluido dentro de los países miembros de la Organización para la Cooperación y el Desarrollo Económicos (OCDE) ha hecho que se asuman como propias las consecuencias de adopción de modelo (Organización para la Cooperación y el Desarrollo Económicos, 2011 y 2018). 


\section{Relación Religión y Escuela}

Frente a todo este desarrollo, es razonable pensar en cuáles son las coordenadas en las cuales se puede desplegar la relación entre la Escuela y la Religión, toda vez que la tendencia laicista del Estado, la comprensión cada vez más natural del acto educativo y la tendencia a comprender los enclaves sociales como enclaves de poder han hecho de las escuelas un bien preciado. Así tenemos que se pueden caracterizar tres posibilidades como las más identificables:

\subsection{La relación como fundadores}

La primera aparición de personas con compromiso religioso como educadores lo tenemos en los tiempos de los primeros evangelizadores del territorio nacional. Ellos fueron (y se mantuvo así durante largo tiempo) religiosos y religiosas Católicos, toda vez que el monopolio de la evangelización les pertenecía casi en exclusividad, aun cuando la reforma protestante (iniciada a inicios del S. XVI) registra un importante avance en América del Norte. La causa directa de este fenómeno está en la casi exclusiva incursión de las Coronas de España y Portugal los que, si bien discuten fuertemente entre ellas por la exclusividad de la acción colonizadora, se someten a la par al arbitrio de la Iglesia Católica, como lo demuestran las soluciones de distribución de territorios de las Bulas Alejandrinas (BejaranoAlmada, 2016).

Las acciones educativas desarrolladas en Chile van en concordancia con lo ordenado por la Corona Española sobre la necesidad de instalar parroquias con Escuelas, disposición presente desde las Leyes de Indias (García-Benítez, 2001). Las primeras del territorio nacional son las fundadas en 1622 por los franciscanos en Quillota, seguidas de Malloa, Copiapó, La Serena y Santiago (García Ahumada, 2008a). Esto era natural, por cuanto la concepción que se tiene de la escuela es como espacio de adoctrinamiento y cultura, entendiéndose la cultura como un acto religioso asociado al conocimiento de las cosas de Dios (Orellana Rivera, 2010). De hecho, la tendencia es a fundar escuelas más cercanas a centro de catequesis o conventos abiertos que a escuelas en el sentido moderno, cuestión que impulsa la mayoría de las escuelas de la época. Así es posible verificar que entre las primeras fundaciones de escuelas anexadas a Conventos y Monasterios (1547), hechos como un acto de religión, hasta los artículos de la Constitución de 1822 (arts. 231, 232, 233) en donde se promueve la fundación de Colegios para la instrucción primaria, anexados a todos los conventos masculinos y los Monasterios de monjas, se oficializa la institución de las escuelas primarias de varones y de mujeres.

Esto hace que la promoción de la Educación tenga directa relación con el desarrollo de la obra misionera de la Iglesia Católica, junto con sus fundaciones monásticas. Ahora bien, esta curiosidad se torna aún mayor cuando recordamos que a inicios del S. XIX, con la instalación de la República de Chile, se funda el Instituto Nacional durante el gobierno de José Miguel Carrera, aunque no por su disposición, sino por la disposición de la Junta de Gobierno que le subroga durante el período en que éste se encuentra combatiendo el ataque del Virrey del Perú. El Instituto Nacional surge como proyecto nacional, asociado a las virtudes de la Religión, asumiendo la orgánica ya instituida por el Convictorio Carolino 
(de creación original jesuita) y absorbiendo la matrícula del Colegio del Santo Ángel de la Guarda (Seminario Conciliar) ${ }^{1}$. Ambas instituciones se funden en 1813 para crear el Instituto Nacional (Guerrero, 2003), aunque luego fue suspendido brevemente en tiempo de la Reconquista y refundado por el Estado en el tiempo de la Patria Nueva (en 1819). De hecho, la misma Constitución de 1822 vela por él "Se procurará conservar y adelantar el Instituto Nacional, cuidando el Supremo Director de sus progresos y del mejor orden, por cuantos medios estime convenientes" (art. 234).

Esta relación muestra que el desarrollo temprano de la institución escolar se da de forma medianamente armónica entre Iglesia Católica y Estado chileno hasta que ocurren tres hechos en desarrollo simultáneo: la promulgación de la Ley de Instrucción Primaria (1860), la fundación de las primeras instituciones educativas religiosas no católicas (1869), y la dictación de Leyes Laicas (1884). Estos tres eventos marcan un punto de inflexión respecto de la posición privilegiada de la Iglesia Católica en el ámbito de la Educación.

\subsection{El cambio de relación de la segunda mitad del S. XIX}

La Ley de Instrucción Primaria de $1860^{2}$ orienta y obliga a la adopción del desafío de la educación por parte del Estado en circunstancias que anteriormente había un fuerte promoción pero en concomitancia con la labor de la Iglesia, así, lo que originalmente era una intención que todos los chilenos y chilenas pudieran leer y escribir (para poder expresar su voluntad), se transforma en la necesidad de generar espacios de instrucción formal luego del interesante experimento de la implantación del sistema lancasteriano en Chile (promovido por O'Higgins), y que resolvía mediamente la escasez de personal docente preparado (Rebolledo Hernández, 2015). La Ley de Instrucción Primaria de 1860 da indicios de la posición que debe adoptar la Iglesia Católica como un actor más del conjunto de actores de la Educación.

Esta posición se refuerza con la fundación de la Escuela Popular en Valparaíso (1869), por parte del Pastor Protestante David Trumbull (1819 - 1889), quien adopta la inquietud de dar un espacio educativo, en modelo de familia cristiana, a los niños de familias protestantes que comienzan a abundar en Valparaíso (Aedo-Richmond, 2000). La presencia de la Iglesia Protestante en Chile tiene su auge en Valparaíso con la llegada de inmigrantes ingleses quienes, favorecidos por el modelo de pastoreo asociado a una familia (autosustentable y no dependiente de la congregación respecto de la castidad de vida) se transforman en agentes educativos de gran alcance. La escuela Popular de Valparaíso resuelve de manera eficiente dos tensiones: la necesidad de educación para las clases populares pero con valores cristianos (las escuelas católicas, según el mismo pastor David Trumbull, eran privativas por su costo) y la necesidad de educación protestante para mujeres, que estaban impedidas de participar de los procesos educativos regulares por las condiciones impuestas en las escuelas católicas (Chile Cristiano, 2019).

\footnotetext{
${ }^{1}$ Esta institución tenía por finalidad preparar Sacerdotes diocesanos, función desarrollada al interior del Instituto hasta que se crea el actual Seminario Pontificio Mayor de Santiago en 1935, con lo que el Instituto deja de tener esta responsabilidad.

${ }^{2}$ Se hace la observación al año para distinguirla de la Ley de Instrucción Primaria Obligatoria de 1920.
} 
Esta obra misionera toma ribetes de proyecto educativo en toda regla prosperando rápidamente y pasando de 4 alumnos, en la primera generación, a 70 antes de los 10 años de existencia. La mitad de ellas eran mujeres, en este punto García Ahumada (2008b, p. 321) afirma que hasta 1910 no tenemos en Chile labor relevante de otras iglesias en Educación que no sea Católica, sin embargo la existencia de este colegio muestra lo contrario. El proyecto educativo religioso no católico se afianza dada la buena instrucción de sus ministros junto con la lógica de responder a una demanda no laica en Educación. Dato importante en este desarrollo es que el mismo David Trumbull poseía el grado de Doctor of Divinity (Kurian et al., 2016), lo que le hace destacar en el panorama educativo, influyendo poderosamente en la configuración de la nueva legislación educativa chilena (Sánchez Gaete, 2011) ya que desde la fundación de la Escuela Popular (actual Colegio Presbiteriano David Trumbull ${ }^{3}$ ) la Iglesia Católica fue desarrollándose en un modelo de colaboración y respeto (la mayoría de las veces) con Protestantes de diversas denominaciones. Así tenemos colaboraciones tan importantes como la relativa a la difusión del evangelio (iniciativa multiconfesional) en 1877 (Sánchez Gaete, 2011), a la par que el desarrollo de fundaciones protestantes como son el Concepcion College y el Colegio Americano de Concepción (para mujeres y hombres, respectivamente) en 1879, el Santiago College (1880), y el Colegio Americano (1887).

Otro elemento clave es la dictación de leyes laicas. El dato fundamental de la creación de una Ley de Cementerio Laico (1883) y una Ley de Registro Civil (1884) hace que la Iglesia Católica pierda relevancia en dos aspectos esenciales: la vida y la muerte (desde el punto de vista civil). Si antes del Registro Civil era necesario estar registrado en un Libro de Bautismos, y eso implicaba (de suyo) que había que estar bautizado, la traducción inmediata era que se necesitaba instrucción religiosa y para eso lo que las parroquias no abarcaban era completado por la escuela, en donde se enseñaba convenientemente el Catecismo en el currículum regular. Así, si no es necesario bautizarse tampoco sería necesario, para estos efectos (ya que en esta secuencia de análisis se deja de lado la discusión sobre el fin sobrenatural del sacramento) enseñar religión en contextos laicos. Cuestión que se ve reforzada por la Ley de Cementerios (Guerra Lira, C., y Universidad de Chile -Dirección de Servicios de Información y Bibliotecas, 2003), ya que antes de la creación de cementerios municipales los infieles debían ser sepultados fuera de los cementerios católicos, muchas veces en las faldas de los cerros (como ocurrió con Santiago) o en los campos de los patrones (como sucedió con los cementerios particulares, populares en el S. XIX en el sur de Chile). La alternativa más usada era junto a los cementerios católicos y luego estos mismos terrenos son convertidos, por el Estado, en cementerios municipales (muchos de los cuales subsisten hasta hoy). Por lo tanto, si no hay temor en la vida o en la muerte, no sería imperante una educación religiosa en contexto escolar.

\footnotetext{
${ }^{3}$ El colegio sigue funcionando en Valparaíso, manteniéndose como uno de los más antiguos del mundo en la tradición de colegios protestantes.
} 


\section{Actual presencia en Educación}

\subsection{El rol del Educador}

Esto refuerza la idea que el mejor rol que puede adoptar la Iglesia es la de educador, de forma particular, a través de sus letrados integrantes, aunque este rol se debe comenzar a compartir con educadores protestantes (el mismo David Trumbull era Dr. En Teología, por lo tanto con un alto nivel de instrucción) que poseían igual instrucción y que, inevitablemente, comienza a compartir su perspectiva religiosa en las aulas.

La segunda posibilidad es la de conservar el rol de sostenedores, entendiendo de manera libre un concepto más bien moderno. Ser sostenedor es ser responsable de la provisión de bienes y recursos a una escuela, cuestión que cada vez más se va perfeccionando a la luz de las transformaciones legales en el ámbito de la Educación, pero que, desde la fundación de la Escuela Popular (actual Colegio Presbiteriano David Trumbull) ha tenido que irse compartiendo entre Católicos y Protestantes de diversas denominaciones, especialmente porque a la Escuela Popular de 1869 le sigue inmediatamente los ya mencionados Santiago College (1880), Concepcion College y Colegio Americano.

\section{2 ¿Qué se enseña entonces en los colegios?}

El anterior panorama cambia la relación de supremacía católica en los colegios, pero modifica también drásticamente la necesidad de la permanencia de la religión en la escuela como dato esencial. Si bien anteriormente la religión tiene un rol social fundamental (bautizarse y morir cristianamente como un imperativo) ahora su rol es más bien secundario. Con todo hay registro que en los planes curriculares del Estado de Chile se conserva la enseñanza de la religión de manera documentada en la educación primaria (Montecinos et al., 2017; Scherz Take, 2015). El antecedente más inmediato, en esta transición entre leyes laicas y separación Iglesia estado lo tenemos en el plan de estudios de 1929 en donde se mantiene, como asignatura, Educación Moral: religión y Moral (con 1 hora en Primer y Segundo año de estudio y 2 horas desde el Cuarto hasta el Sexto año de estudios). Antes de las leyes laicas y la transformación de modelo de provisión tenemos clases de "Teología Dogmática" y "Sagrada Escritura" (Instituto Nacional), o "Historia del Antiguo y Nuevo Testamento" (Reforma de Barros Arana), o "Historia Sagrada" (plan de estudio de humanidades, de 1875).

Con el cambio de perspectiva respecto de la posición y razón de la religión en la escuela, se origina el conflicto de qué se debe enseñar, por lo cual la religión debe enfrentar la pregunta de si se debe enseñar historia de la Religión (incluyendo las fracturas, divisiones y reuniones) o si se debe enseñar catecismo (con el conflicto doctrinal que esto implica). Esto, sumado a la explosiva expansión de iglesias con denominaciones protestantes (Mansilla et al., 2017), hacen que la enseñanza de la religión en la escuela pase por fases de conflicto ya que se debe resolver qué enseñar y asimismo, dependiendo de la opción, quiénes deben enseñar. Pajer (Pajer, 2015), presenta tres alternativas de enseñanza de la religión a nivel mundial: Un modelo político-concordatorio, en donde se enseña la religión 
como consecuencia de la convivencia y acuerdo entre Estado e Iglesia, un modelo Académico-curricular, en donde se enseña la religión en función de su valor académico y el proyecto curricular de la nación-escuela, y un modelo Ético-Valórico, en donde se justifica la enseñanza en virtud de la promoción de los valores de respeto por la libertad e individualidad de los grupos coexistentes en el espacio escolar.

En el caso de Chile, la particularidad de la permanencia de la clase de religión dentro del curriculum nacional, en concordancia con la trayectoria internacional, hace que la pregunta se establezca sobre qué se enseña efectivamente en la clase de Religión, ya que el contenido obliga a pensar en la metodología de enseñanza. Si bien la vinculación religión / iglesia aparecía anteriormente como un ejercicio inmediato, no es así a nivel curricular, dado que la perspectiva asumida determina también qué contenidos se privilegiarán.

\section{Los principales conflictos}

Ante esto se comienzan a generar las primeras reacciones de conflicto entre Iglesias, especialmente por la consideración por parte de las denominaciones protestantes de la inadecuada participación que tienen la Iglesia Católica en la clase de Religión, que no respondería a los deseos de los alumnos y alumnas protestantes.

\subsection{La “Ley Muñoz Cornejo” de 1944}

El primer gran conflicto en ese sentido es el generado en torno a la conocida como "Ley Muñoz Cornejo", propuesta que planteaba que la enseñanza de la Religión en los colegios se debía solucionar enseñando unitariamente Religión Católica, en lo cual advirtió el mundo protestante un real conflicto por la exclusión que de ellos significaría. Por parte de la Iglesia Metodista Pentecostal se releva el rol del entonces pastor Rvdo. Manuel Umaña Salinas en la organización y liderazgo de las protestas en contra de esta propuesta. El Rvdo. Umaña posteriormente es ungido obispo (en 1950) de su congregación y siguió liderando, con gran relevancia para el país, las acciones de promoción de la Iglesia. La normativa es retirada pero no resuelta, ya que el conflicto vuelve a presentarse en forma de propuesta en tiempos de Eduardo Frei Montalva.

La marcha de 1944 tiene la particularidad de adoptar la estructura tradicional de los movimientos sociales y de las procesiones religiosas, cuestión particularmente significativa al realizarse desde la plaza de armas hacia el antiguo congreso nacional, "Esta marcha convenció a la Cámara de Diputados que dicha ley no se debía aprobar" (Canales, 2000).

\subsection{La oficialización curricular de la religión, de 1984}

Actualmente, y desde el año 1983, la Educación Religiosa Escolar en Chile está resguardada en el contexto escolar municipal a través del Decreto $N^{\circ} 924$ (1984) que estipula se debe impartir, en modalidad de obligatorio en cuanto a su oferta, pero optativo en cuanto a su aceptación, la asignatura de Religión con una duración de 2 horas semanales en todos los establecimientos del país. Esta indicación surge en un contexto y tiempo determinados, particularmente basados en la concepción que la mayoría de los chilenos se 
declaraba católicos y, por ende, tuvo entre las primeras opciones de clases de Religión la impartida según las orientaciones de la Religión Católica, dado que la Iglesia Católica presentó para aprobación del Ministerio de Educación Planes y Programas de religión para la Enseñanza Media Científico Humanista en el año 1983, los que fueron usados como guía (Decreto $N^{\circ} 158$ Exento, 1983). No obstante lo anterior, para los colegios confesionales muchas veces los planes y programas de religión para la enseñanza básica fueron reemplazados por programas propios de Congregaciones. Asimismo se extiende la propuesta de planes de estudio para la Educación Técnico - Profesional por el Ministerio de Educación a través del Decreto $N^{\circ} 68$ (1987).

A la par de este proceso todas las Iglesias y denominaciones confesionales distintas de la Iglesia Católica con presencia en la Educación fueron aprobando sus respectivos planes de Estudio. En el año 1984, fueron aprobados los Planes y Programas de Religión Evangélicos (Ruz Vargas y Fredes Serrano, 1984), presentados por 23 congregaciones y organizaciones agrupadas con la intención de representar una alternativa para los estudiantes que no participaban de la clase de religión según el programa católico, pero que deseaban tener clases cercanas a su credo. En 1985 se aprobaron los planes y programas de estudio de la Religión Anglicana (D. 75, exento), en 1988 los planes de estudio de la religión Ortodoxa (D.145, Exento), en 1991 los planes de estudio de la religión Presbiteriana (D. 289) y los de la religión Ba'hai (D. 266, exento), en 1993 los planes de estudio de la Corporación Iglesia Evangélica Luterana de la república de Chile (D. 433), totalizando a la fecha 16 opciones diversas para su implementación (Cárdenas Fuentealba, 2004). Asimismo los planes y programas de estudio de religión Católica sufren modificaciones y actualizaciones los años 1996 y 2005, siendo esta última fecha la de aprobación de la última versión vigente (Conferencia Episcopal de Chile, 2005). La propuesta de planes de estudio para las iglesias evangélicas también es modificada, aprobándose el año 2017 nuevos programas (Iglesia para la Doctrina Cristiana y Comité Nacional de Educación Evangélica, 2017). Finalmente, mediante el decreto 373/2020, fueron aprobados los nuevos programas de estudio de Religión Católica, que incorporan un giro metodológico, pedagógico y antropológico respecto del anterior programa, aumentando la coherencia entre la propuesta particular de la Religión y la reforma y ajuste curricular de la Educación Chilena. Con todos estos elementos, cada establecimiento debe ofrecer la asignatura de Religión, sin que necesariamente signifique que la elección del estudiante represente la necesidad de aprendizaje autónomo, ni que en las distintas opciones de asignatura se ofrezca elementos similares enfrentados desde distinta perspectiva.

\subsection{Actuales conflictos}

En un primer momento las clases de Religión fueron asumidas por dos tipos de actores: profesores, muchos de ellos sin formación específica en Religión, pero con disponibilidad horaria, o agentes pastorales con experiencia en Catequesis, pero sin un desempeño pedagógico comprobable o acorde a lo esperable. Esta situación pretendía finalizarse el año 2003 con la regulación de los requisitos exigidos para el ejercicio de la pedagogía (Decreto $N^{\circ} 352,2004$ ), pero, particularmente para el caso de los profesores de religión, esta norma se modificó extendiéndose el plazo hasta el 31 de diciembre de 2008 
(Decreto 168), ocasión en que nuevamente fue prorrogado el plazo (DecretoN ${ }^{\circ} 361$ ) hasta el año 2010 y luego (Decreto $N^{\circ}$ 436) hasta el año 2013 (Decreto $N^{\circ}$ 436, 2010). Para la fecha indicada estaban en pleno proceso de consolidación las carreras de Pedagogía en Religión Católica impartido, bajo diversos nombres, por varias universidades del país, sin embargo, otras religiones requerían habilitar a sus profesores por no contar con profesionales idóneos en suficiente número para cubrir la creciente demanda en los colegios. El año 2013 el Comité Nacional de Educación Evangélica - Conaev y la Red de Colegios Evangélicos de Chile - Resech - solicita la prórroga, por última vez, de la fecha de vencimiento del plazo para el ejercicio docente de personas sin formación pedagógica (Decreto $N^{\circ} 618,2014$ ), la que se confiere perentoriamente hasta el 28 de febrero de 2021, gracias a una modificación de un artículo transitorio del 06 de marzo de 2019 (Decreto $\mathrm{N}^{\circ} 352,2004$ ).

Recién a partir del año 2015, a través de la aplicación estricta del procedimiento de habilitación docente, se ejecutorió la obligatoriedad de tener formación pedagógica (incluso en grado de incompleta) o cuando menos formación profesional de 8 semestres para poder ejercer de profesor (Decreto $N^{\circ} 352,2004$ ). Con esta norma, contenida en la Ley General de Educación, se inició el proceso masivo de retiro de docentes no profesores autorizados.

\section{Conclusiones}

La actual revisión de la historia de la generación de modelos educativos desde el cristianismo y su expresión en la Iglesia Católica, junto con la verificación de su rol y pervivencia dentro del sistema educacional chileno, nos lleva a constatar que muchas de las acciones son soluciones a la mantención de espacios de acción desde la Iglesia en el mundo de la Educación, tanto a nivel de sostenedores, como de profesores. Esta vía ha sido desarrollada indistintamente por diversas iglesias, denominaciones y congregaciones religiosas. Sin embargo, su pervivencia no responde únicamente a un deseo particular de la misma institución por mantenerse inserta, sino que responde a un proceso natural en donde la Educación, tanto a nivel universal como a nivel local, siempre ha sido desarrollada e incluso ha sido potenciada, por la acción de la Iglesia. Negar la importancia de la Iglesia para estos fines es negar la dependencia histórica que se posee, desde la creación de la República de Chile, de la acción de la misma para el desarrollo de la Educación.

Otro elemento distinto es la discusión sobre la pertinencia de mantener en el currículo escolar chileno la asignatura "religión", ya que si bien no es un acto arbitrario carente de tradición (dado que se viene impartiendo desde los más antiguos programas de estudio de instituciones dependientes del Estado de Chile), sí es un contenido curricular que como todos los contenidos es factible de ser revisado, actualizado o reemplazado por una instancia similar. La multiplicidad de ofertas de programas de Religión tiende a influir en este aspecto ya que se manifiesta su plasticidad en contenidos y variabilidad de perspectivas desarrolladas. 


\section{Referencias Bibliográficas}

Aedo-Richmond, R. (2000). La educación privada en Chile. Un estudio histórico analítico desde el período colonial hasta 1990. Santiago de Chile: RIL Editores.

Andrades Rivas, E. (2017). La transformación de la ciudadanía romana en el fin del Imperio. Revista de estudios histórico-jurídicos,(39), 61-83. https://doi.org/10.4067/S071654552017000100061

Bárcena Orbe, F. B. (1989). Explicación de la Educación como práctica moral. Revista Española de Pedagogía, 47(183), 245-278. https://bit.ly/30PxIDq

Bejarano-Almada, M. d. L. (2016). Las Bulas alejandrinas. Detonantes de la evangelización en el Nuevo Mundo. Revista de El Colegio de San Luis, 6(12), 224-257. https://bit.ly/39Aa2Bu

Boff, L. (2002). El cuidado esencial. Ética de lo humano, compasión por la Tierra (J. Valverde, Trad.). Madrid: Trotta.

Calderón, H. y González, E. (2006). Acerca de dónde enseñaron Sócrates, Platón y Aristóteles o sobre el silencio de los espacios dialogantes. Uni-Pluriversidad, 6(1), 41-46. https://bit.ly/3hCGjdW

Cárdenas Fuentealba, N. (2004). Enseñanza de religión en los establecimientos educacionales (Memoria de Licenciatura). Universidad Austral de Chile, Facultad de Ciencias Jurídicas y Sociales. https://bit.ly/2EkXsuf

Chile Cristiano. (2019). David Trumbull. http://chilecristiano.cl/index.php/precursores/davidtrumbull/84-david-trumbull

Conferencia Episcopal de Chile (2005). Programa de Educación Religiosa Católica, Sector de Aprendizaje Religión. Santiago de Chile: SM Chile S. A.

Congreso Jeneral de Enseñanza Pública (1903). Actas i trabajos (Vol. 1). Santiago de Chile: Imprenta Barcelona. https://bit.ly/3hw9wHa

Constitución Política del Estado de Chile. Santiago, Chile, 30 de octubre de 1822. http://bcn.cl/2f1a0

Costa Grillo, J. G. y Abreu Funari, P. P. (2015). El Culto Imperial Romano y el Cristianismo inicial, algunas consideraciones. Revista Mundo Antigo, 4(8), 49-65. https://bit.ly/2CHb7LT

Decreto $N^{\circ} 68$ Exento. Diario Oficial de la República de Chile, Santiago, Chile, 13 de mayo de 1987. http://bcn.cl/2f0ue

Decreto N 158 Exento. Aprueba programas de Religión Católica para Educación Media Humanístico -Científica. Diario Oficial de la República de Chile, Santiago, Chile, 26 de agosto de 1983. http://bcn.cl/2f0u1

Decreto No 924. Reglamenta clases de Religión en Establecimientos Educacionales. Diario Oficial de la República de Chile, Santiago, Chile, 07 de enero de 1984. http://bcn.cl/2f0u6

Decreto $\mathrm{N}^{\circ}$ 352. Reglamenta Ejercicio de la función docente. Diario Oficial de la República de Chile, Santiago, Chile, 12 de marzo de 2004. http://bcn.cl/2ezqd 
Decreto $N^{\circ}$ 436. Modifica Decreto n 352, de 2003, que reglamenta ejercicio de la Función Docente. Diario Oficial de la República de Chile, Santiago, Chile, 27 de diciembre de 2010. http://bcn.cl/2ernz

Decreto $N^{\circ}$ 618. Modifica decreto 352, de 2003, que reglamenta el ejercicio de la función docente. Diario Oficial de la República de Chile, Santiago, Chile, 4 de marzo de 2004. http://bcn.cl/2ezqq

De León Lázaro, G. (2013). La Educación en Roma. Anuario jurídico y económico escurialense, (46), 469-482. https://bit.ly/2EkXsuf

Den Heyer, C. J. (2003). Pablo: un hombre de dos mundos (J. Valiente Malla, Trad.). Barcelona: El Almendro.

Egaña Barahona, M. L., Núñez Prieto, I., y Salinas Álvarez, C. (2003). La educación primaria en Chile, 1860-1930. Una aventura de niñas y maestras. Santiago de Chile: LOM Ediciones.

Egido Serrano, J. (2013). Más que los gorriones. Madrid: PPC.

Faubell Zapata, V. (2000). Educación y órdenes y congregaciones religiosas en la España del siglo XX. Revista de educación (Madrid. Internet), (Extraordinario), 137-200. https://bit.ly/2WWh923

Fernández Eyzaguirre, S. (2007). Jesús. Los orígenes históricos del cristianismo desde el año 28 al 48 d. C. Santiago de Chile: Pontificia Universidad Católica de Chile.

García Ahumada, E. (2008a). Las congregaciones religiosas en la historia de la Educación Chilena. Pensamiento educativo, 42(1), 43-56. https://bit.ly/300eXun

García Ahumada, E. (2008b). Los cristianos en la historia de la educación. Autocrítica. Anuario de la Historia de la Iglesia, 17, 321-323. https://bit.ly/33feCUH

García-Benítez, A. (2001). Sociedad y Educación en las Leyes de Indias. Barataria (Olías del Rey. Internet), (4), 259-274. https://doi.org/10.20932/barataria.v0i4.281

González, D. (2007). Escuela de traductores de Toledo. Infodiversidad, 11, 77-88. https://bit.ly/3gOMCHG

Guerra Lira, C., \& Universidad de Chile -Dirección de Servicios de Información y Bibliotecas. (2003). Fuentes documentales y bibliográficas para el estudio de la historia de Chile. http://www.historia.uchile.cl/CDA/fh_index/index.html

Iglesia para la Doctrina Cristiana y Comité Nacional de Educación Evangélica. (2017). Programa de Religión Evangélica Enseñanza Básica. https://bit.ly/3f80xIW

Jara Hinojosa, I. (1998). Algunas significaciones culturales de la educación: el caso de la Ley de Instrucción Primaria Obligatoria en Chile. Revista chilena de humanidades, (18/19), 71-105. https://bit.ly/30QURzN

Kurian, G. T., Lamport, M. A., \& Marty, M. E. (2016). Encyclopedia of Christianity in the United States. Lanham, MD: Rowman \& Littlefield.

Leiva, C. (2005). Conductismo, cognitivismo y aprendizaje. Tecnología en Marcha, 18 (1), 6673. https://bit.ly/2EpAouo 
Levin, H. M. (2015). Investing in People: The Economics of Population Quality. Theodore W. Schultz. American journal of education, 91(1), 131-135. https://doi.org/10.1086/443677

León Salazar, A. (2007). Qué es la educación. Educere, 11(39), 595-604. https://bit.ly/330NB6X Mansilla, M. Á., Leiva, S., y Muñoz, W. (2017). Pospentecostalismo: del fundacionalismo al postfundacionalismo pentecostal chileno. Cinta de moebio, (59), 172-185. https://doi.org/10.4067/S0717-554X2017000200172

Montecinos, C., Moya, L., Vargas, F., Berkowitz, D., y Cáceres, P. (2017). Caracterización de la enseñanza de la religión a partir de la implementación del Decreto 924/1983 en las escuelas públicas de Chile. https://bit.ly/39yGKTR

Morales, F. (2010). La Iglesia de los frailes. En M. Menegus Bornemann, F. Morales, \& Ó Mazín Gómez (Autores), La secularización de las doctrinas de indios en la Nueva España. La pugna entre las dos iglesias (pp. 13-76). México, DF: Bonilla Artigas Editores. https://bit.ly/32ZM0yr

Moreno Resano, E. (2013). Constantino y su relación personal con el cristianismo: de la piedad tradicional a la conversión. 'llu (Madrid. Internet), 18, 175-200. https://doi.org/10.5209/rev_ILUR.2013.v18.43047

Núñez Prieto, I. (2007). La profesión docente en Chile: Saberes e identidades en su historia. Pensamiento Educativo, 41(2), 149-164. https://bit.ly/3hFjmGY

Núñez Prieto, I. (2010). Escuelas Normales: Una historia larga y sorprendente. Chile (18421973). Pensamiento Educativo, 46(1), 133-150. https://bit.ly/303ZMhr

Congreso Nacional Pedagójico. (1890). Resumen de las discusiones, actas i memorias presentadas al Primer Congreso Pedagógico celebrado en Santiago de Chile en septiembre de 1889 (J. A. Núñez, Dir.). Santiago de Chile: Imprenta Nacional. https://bit.ly/39yuVgc

Organización para la Cooperación y el Desarrollo Económicos. (2011). La medición del aprendizaje de los alumnos. Mejores prácticas para evaluar el valor agregado en las escuelas. OECD Publishing. https://doi.org/10.1787/9789264090170-es

Organización para la Cooperación y el Desarrollo Económicos. (2018). Educación en Chile, Revisión de Políticas Nacionales de Educación. México, DF: OECD Publishing. https://doi.org/10.1787/9789264288720-es

Oliver, J. (2000). La vida monástica en la iglesia. (Institución Fernando el Católico, Ed.). En IV Jornadas de canto gregoriano. Los monasterios aragoneses (pp. 11-28). Zaragoza: Institución Fernando el Católico. https://bit.ly/302B41a

Orellana Rivera, M. I. (2010). Una mirada a la escuela chilena. Entre la lógica y la paradoja. Santiago de Chile: DIBAM. https://bit.ly/3jly4yF

Ospina Rave, B. (2008). La educación como escenario para el desarrollo humano. Investigación y educación en enfermería, 26(3), 12-15. https://bit.ly/2DgrD55

Pagan, C. J. (2011). La pedagogía de Jesús. Santiago de Chile: Instituto Pastoral Apóstol Santiago. https://bit.ly/305QhyE

Pajer, F. (2015). Cómo y por qué Europa enseña las religiones en la escuela. Los tres paradigmas. REER (Valparaíso), 5(1), 1-24. https://bit.ly/3079UGy 
Polanco, R. (2003). La Iglesia como espacio sagrado de encuentro. Teología y vida, 44(2/3), 332-345. https://doi.org/10.4067/S0049-34492003000200014

Ponce de León Atria, M. (2010). La llegada de la Escuela y la llegada a la Escuela: La extensión de la Educación Primaria en Chile, 1840-1907. Historia, 43(2), 449-486. https://bit.ly/2X3XH3j

Ramírez Iñiguez, A. C. (2017). La educación con sentido comunitario: reflexiones en torno a la formación del profesorado. Educación (Lima. 1992. En línea), 26(51), 79-94. https://doi.org/10.18800/educacion.201702.004

Rebolledo Hernández, A. (2015). La cultura. Chile (1808-1830). Taurus. https://bit.ly/3fdASRb

Romero, M. (2004). Credibilidad de la Iglesia y desafíos a la pastoral. Teología y vida, 45(2/3), 353-365. https://doi.org/10.4067/S0049-34492004000200009

Ruz Vargas, I., y Fredes Serrano, L. (1984). Programa de Educacional de Religión Evangélica. Santiago de Chile: Comité Nacional de Educación Evangélica. https://bit.ly/302LSMF

Sandoval Vásquez, J., y Hernández Castro, G. (2018). Crítica a la teoría del capital humano, educación y desarrollo socioeconómico. Ensayos pedagógicos (En línea), 13(2), 137-160. https://doi.org/10.15359/rep.13-2.7

Scherz Take, T. (2015). La enseñanza de la Religión en las escuelas, urgencia educativa para la esfera pública. Santiago de Chile: Vicaría de la Educación. https://bit.ly/3f2M6aR

Schultz, T. W. (1961). Investment in Human Capital. The American economic review, 51(1), 117. https://bit.ly/3jFmfJL

Senado de la República de Chile. (5 de Diciembre de 2005). La educación en el siglo XIX a través de las Leyes Emblemáticas. https://www.senado.cl/la-educacion-en-el-siglo-xix-atraves-de-las-leyes-emblematicas/senado/2014-12-02/162845.html

Serrano Pérez, S., Ponce de León Atria, M., y Rengifo Streeter, F. (2012). Historia de la Educación en Chile (1810-2010). Santiago de Chile: Taurus. https://bit.ly/2BBiVOt

Soto Roa, F., y Núñez Prieto, I. (2004). Para iniciarse en la historia escolar chilena. Revista de Educación, (315), 4-9. https://bit.ly/3g6oS4R

Sánchez Gaete, M. (Dir.). (2011). Historia de la Iglesia en Chile. Los nuevos caminos: La iglesia y el estado (Vol. 3). Santiago de Chile: Editorial Universitaria de Chile.

Villar, J. R. (1993). Creo en la Santa Iglesia Católica. Scripta theologica, 25(2), 601-626. https://bit.ly/2P7v14V

\section{Para citar este artículo bajo Norma APA 7a ed. \\ Vega Ramírez, J. F. A. (2020). La presencia de religión en la educación y escuelas chilenas. Cuadernos de teología - Universidad Católica del Norte (En línea), 12, e4049, https://doi.org/10.22199/issn.0719-8175-2020-0002}

Copyright del articulo: @2020 Javier F. A. Vega Ramírez

Este es un artículo de acceso abierto, bajo licencia Creative Commons BY 4.0.

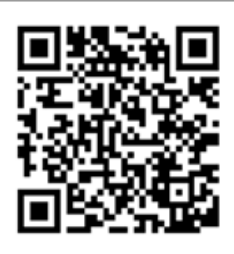

DOI

(cc) BY 